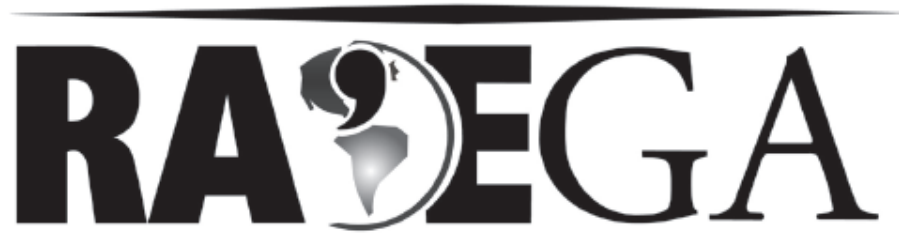

O ESPAÇO GEOGRÁFICO EM ANÁLISE

\title{
ANÁLISE DA PLUVIOMETRIA PARA DEFINIÇÃO DE ZONAS HOMOGÊNEAS NO ESTADO DO PARANÁ
}

\section{RAINFALL ANALYSIS TO DEFINE HOMOGENEOUS PLUVOMETRIC AREAS IN THE STATE OF PARANA}

\author{
Elenice FRITZSONS ${ }^{1}$ \\ Luiz Eduardo MANTOVANI ${ }^{2}$ \\ Marcos Silveira WREGE ${ }^{3}$ \\ Anselmo CHAVES NETO ${ }^{4}$
}

\section{RESUMO}

O Estado do Paraná apresenta grande variabilidade climática por estar situado numa área de transição entre regimes de clima tropical e temperado. O objetivo do trabalho foi definir e analisar algumas variáveis pluviométricas mais significativas em termos ambientais para utilizá-las na composição de zonas pluviométricas homogêneas. Foram utilizados dados pluviométricos de 469 postos meteorológicos, obtidos num período de 30 anos. Os dados foram submetidos às análises de Componentes Principais e de Agrupamento. Concluiu-se que as precipitações de inverno e verão foram importantes para o agrupamento de zonas. Onde há menor pluviometria, há maior diferença entre os trimestres de verão e também nos de inverno e a precipitação de verão é mais concentrada. Nas áreas de maior pluviometria, no sudoeste do Estado, ocorrem as mais elevadas precipitações de inverno e no litoral do Paraná, as

1 Agrônoma, Doutora em Eng. Florestal, pesquisadora da Embrapa Florestas (Colombo-Pr). elenice@cnpf.embrapa.br

${ }^{2}$ Geólogo, Doutor em Geologia, professor do Depto de Geologia da Universidade Federal do Paraná. lem@ufpr.br

\footnotetext{
Agrônomo, Doutor em Agronomia, pesquisador da Embrapa Florestas (Colombo-Pr). wrege@cnpf.embrapa.br

4 Matemático e Engenheiro Civil. Doutor em Eng. Elétrica, professor do Depto de Estatística da Universidade Federal do Paraná. anselmo@ufpr.br
} 
chuvas de verão assumem um maior peso na precipitação total anual. Há uma zona intermediária, no centro do Estado, que constitui uma zona de transição, onde os grupos ficaram mais dispersos.

Palavras chave: precipitação; análise multivariada; clima; recarga de aqüíferos, Paraná.

\begin{abstract}
The Paraná State has great climate variability due its situation in a transition area between tropical and temperate zones. The objective of this work was to define and analyze some environmentally important variables linked to rainfall for definition of homogeneous rainfall zones. The precipitation data from 469 meteorological stations were obtained over a period of 30 years. Data were analyzed by Principal Component Clustering analysis. It was concluded that winter and summer precipitations were two important variables to form groups. In the regions of lower rainfall there is greater difference between the quarters of summer and of the winter and the concentration of the precipitation occurs in the summer. The areas of greatest rainfall are located at the Southwest where the highest rainfall arrives in winter. The coast of Paraná too, where the summer rains represent greater weight in the total annual rainfall. There is an intermediate zone located in the center of the state, which is a transition zone, where the groups were widely dispersed.
\end{abstract}

Key words: precipitation; multivariate analysis; climate; aquifers recharge, Paraná.

\title{
INTRODUÇÃO
}

A precipitação pluviométrica, incluindo os seus atributos de quantidade e distribuição ao longo do ano, conjugada às variáveis térmicas e higrométricas, aos diversos tipos de substratos geológicos e coberturas pedológicas que ocorrem ao longo dos compartimentos da paisagem, modulam, em conjunto e de forma sinergética, a distribuição dos biomas na terra.

A compreensão das características pluviométricas das regiões é de extrema importância para o desenvolvimento das pesquisas hídricas, hidrogeológicas, recarga de aqüíferos, para o setor agrícola e florestal, para o planejamento ambiental e também para o estudo das mudanças climáticas, uma vez que referencia a pluviometria regional ao longo do tempo.

O Estado do Paraná, na região Sul do Brasil, possui uma área de 199.315 km2 (IBGE, 2010) que se distribui entre as regiões tropicais e subtropicais de altitude. Apresenta uma paisagem diferenciada decorrentes da diversidade climática; do 
substrato geológico, onde se destacam os basaltos continentais e suas coberturas areníticas do Terceiro Planalto, os estratos sedimentares síltico-argilosos do Segundo Planalto e as rochas metamóficas e graníticas do Primeiro Planalto e litoral; do relevo com áreas serranas a leste e planaltos relativamente elevados no interior cortados por calhas fluviais; da densa rede hidrográfica; de solos bastante diferenciados em termos físicos e químicos; da vegetação que inclui savanas (cerrados), campos, florestas; além de extensas áreas agrícolas, pastoris e de reflorestamentos.

De acordo com Souza, 2006, não há, em princípio, déficit hídrico em nenhuma parte de território paranaense. Entretanto, considerando as culturas anuais, ocorre déficit hídrico no Norte e Noroeste do Estado, principalmente em locais de solos rasos e arenosos, a exemplo de áreas sobre o Arenito Caiuá; enquanto no litoral ocorre estresse hídrico pelo excesso de água.

De acordo com os estudos feitos pelo IAPAR (2010), baseado na classificação de Koeppen, há dois tipos de clima no estado: Cfa (Clima subtropical com tendência de concentração das chuvas nos meses de verão, contudo sem estação seca definida), o Cfb (Clima temperado sem estação seca definida). O Cfa ocupa a porção norte, oeste e grande parte do sudoeste e uma parte da região sul (Vale do Ribeira), enquanto que o Cfb predomina na porção sul do estado. Entretanto, de acordo com o ITCG (2008) há 9 tipos climáticos (Af, Cfa, Cfa/Af, Cfa/Cwa, Cfb, Cfb/Cfa, Cwa, Cwa/Cfa) com nítido predomínio do Cfa e Cfb.

Entretanto, mesmo dentro do grupo Cfa e Cfb há forte variabilidade climática, especialmente pelo fato do Paraná estar sob o trópico de Capricórnio ( $23^{\circ} 27^{\prime} \mathrm{S}$ ), na transição entre o tropical e o temperado quente, além de possuir o litoral mais úmido da região sul do Brasil (Nimer, 1979). A carta de registro de focos de incêndio no Estado do Paraná (SAMIFS, 2010) também evidencia esta heterogeneidade climática, pois na porção norte e central há uma incidência moderada a alta de focos, enquanto que na porção sul e leste a incidência é moderada a nula.

Considerando estes aspectos, o objetivo principal deste trabalho é o de definir e analisar algumas variáveis pluviométricas mais importantes para utilizá-las na composição de zonas pluviométricas homogêneas no Estado do Paraná, utilizando a análise estatística multivariada e, assim, oferecer novos subsídios em termos de informação, às pesquisas ecológicas, hidrológicas, hidrogeológicas e ambientais para o Estado do Paraná. 
Para o tratamento dos dados climáticos, a análise de agrupamento é bastante útil, tendo sido utilizada nos trabalhos de Falvo et al. (1996), Tristão et al. (1997), Bernardes (1998), Reis et al. (1999) e Andrade et al. (2000), para separar conjuntos de estações pluviométricas com características homogêneas.

Estudos deste tipo também foram empreendidos por Diniz et al. (2003), que definiram áreas homogêneas quanto às temperaturas máximas e mínimas no Rio Grande do Sul. Keller Filho et al. (2005) consideraram a análise de agrupamento hierárquica como um instrumento adequado na identificação de zonas homogêneas quanto ao regime de chuva. Fritzsons et al. $(2009,2010)$ também utilizaram a análise de agrupamento para propor uma divisão climática do Estado do Paraná, baseada em diversos parâmetros climáticos.

No exterior, Unal et al. (2003) propuseram uma nova divisão climática da Turquia utilizando a análise de agrupamento, tendo como base a temperatura e precipitação. Venkatesh e Joe (2007), em trabalho realizado na Índia, encontraram três zonas com regimes distintos de precipitação, utilizando a análise de cluster e análise de variância. Williams et al. (2010), em trabalho de ecorregionalização do Estado de Yowa (EUA), utilizaram um conjunto de técnicas que inclui análise multivariada e geoprocessamento.

\section{MATERIAL E MÉTODOS}

Neste trabalho foram utilizados dados pluviométricos de 469 postos no Estado do Paraná, obtidos num período de 30 anos (1977 a 2006). Os dados foram provenientes do Departamento Nacional de Águas e Energia Elétrica (DNAEE), da COPEL, SUDERHSA, entre outras instituições, atualmente agrupados pela Agência Nacional de Águas (ANA).

Para determinar as zonas climáticas, primeiramente, foram definidas as variáveis classificatórias que seriam utilizadas na análise de agrupamentos. Depois de definidas, elas foram submetidas à Análise de Componentes Principais para definir a relação entre as componentes (variáveis) e sua importância relativa. Posteriormente, utilizou-se a Análise de Agrupamento (Cluster's Analysis - método Ward's) para visualização dos grupos formados pelas estações, tendo como base as variáveis classificatórias. A partir daí determinou-se o número de grupos para divisão dos postos 
pluviométricos, os quais foram utilizados na aplicação do método de agrupamento não hierárquico das K- Médias.

\section{Variáveis classificatórias}

No Estado do Paraná há uma forte distinção entre áreas onde ocorre estiagem de grau variável no inverno, assemelhando-se ao clima tropical (Cfa), e áreas onde a precipitação é mais constante ao longo do ano, inclusive no inverno, de clima temperado ( $\mathrm{Cfb})$. Assim, as variáveis escolhidas para proceder às análises foram: média do total de precipitação anual, média dos totais de precipitação dos meses de verão: dezembro, janeiro e fevereiro (DJF), as precipitações de inverno: junho, julho, agosto (JJA), a diferença das precipitações entre os meses de verão e inverno (DET) e a precipitação total anual (Total).

\section{Análise de Componentes principais}

Depois de definidas as variáveis classificatórias, elas foram submetidas à "Análise de Componentes Principais", a qual fornece as ferramentas adequadas para identificar as variáveis mais importantes no espaço das componentes principais. De acordo com Moita Neto, 2010, das características desta análise, pode-se destacar: a) as variáveis podem ser analisadas separadamente devido à ortogonalidade, servindo para interpretar o peso das variáveis originais na combinação das componentes principais mais importantes e b) servem para visualizar o conjunto da amostra apenas pelo gráfico das duas primeiras componentes principais, que detêm maior parte da informação estatística. Assim, tem-se uma idéia da importância das variáveis classificatórias e da relação entre elas.

\section{Método de agrupamento}

As variáveis classificatórias foram submetidas ao processo de agrupamento, que objetiva compor grupos com elevada homogeneidade interna, dentro dos grupos, e uma elevada heterogeneidade externa, entre os grupos. Há dois tipos de métodos de agrupamento: métodos não-hierárquicos, que produzem um número fixo de agrupamentos e métodos hierárquicos, que formam agrupamentos por meio de uma seqüência crescente de partições de grupos - abordagem divisiva - ou de junções sucessivas de grupos - abordagem aglomerativa. 
Neste trabalho foi utilizado, primeiramente, o método hierárquico de variância mínima (Ward's method) para agrupar estações pluviométricas com dados semelhantes. O método de Ward, de acordo com Hair et. al. (2005), forma grupos de maneira a atingir sempre o menor erro interno entre os vetores que compõem cada grupo e o vetor médio do grupo, o que equivale a buscar o mínimo desvio padrão entre os dados de cada grupo. O resultado pode ser visualizado por meio de um dendrograma.

Com a observação do dendrograma, formado pelo método de Ward e do gráfico da distância para aglomeração, foi definido um número de grupos, o qual foi submetido ao método das K- Médias. De acordo com Seidel et al. (2008), este método é o mais utilizado quando há muitos objetos a serem agrupados com pequenas variações, como é o caso. Os grupos, depois de formados, foram demarcados na carta hipsométrica para verificação da consistência ambiental do agrupamento.

\section{RESULTADOS E DISCUSSÃO}

O resultado da estatística descritiva pode ser visualizado na Tabela 1.

Tabela 1. Estatísticas descritivas das variáveis classificatórias das 469 estações pluviométricas do Estado do Paraná entre 1977 e 2006 (30 anos)

$\begin{array}{lllll}\text { Parâmetros estatísticos } & \text { Total } & \text { DET } & \text { DJF } & \text { JJA } \\ \text { Média do total }(\mathrm{mm}) & 1695,8 & 243,8 & 533,9 & 290,0 \\ \text { Desvio padrão } & 260,7 & 101,2 & 77,8 & 80,6 \\ \text { Coeficiente de variação } & 15,37 \% & 41,49 \% & 14,58 \% & 27,80 \% \\ \text { Valor mínimo }(\mathrm{mm}) & 1133,6 & 16,9 & 421,2 & 147,3 \\ \text { Valor máximo }(\mathrm{mm}) & 2701,7 & 709,2 & 1037,5 & 482,3 \\ \text { Amplitude }(\mathrm{mm}) & 1568,1 & 692,3 & 616,3 & 335,0\end{array}$

Nota1: Total - média da precipitação total anual; DET- diferença entre as médias das precipitações dos trimestres de verão e de inverno; DJF- média da precipitação total de dezembro, janeiro e fevereiro; JJA média da precipitação total de junho, julho e agosto.

Assim, verifica-se que no Estado do Paraná para o período estudado, que o valor do total da menor precipitação anual foi de $1134 \mathrm{~mm}$ (Cornélio Procópio, estação 2350057, Ponte Preta, bacia do baixo Tibagi, ANA) e o valor do total da maior precipitação anual foi de 2702 mm (Guaraqueçaba, estação 2548042, Rio Guaraqueçaba, bacia litorânea, SUDERHSA). Nimer (1979) observa que no litoral do estado do Paraná ocorre a precipitação mais elevada do sul Brasil, e que isso decorre das entradas de frentes polares, associadas ao relevo de escarpas abruptas. 
Há forte amplitude de variação entre os trimestres de inverno e verão (16,9 a 709,2 $\mathrm{mm}$ ), o que condiz com a transição climática em que se encontra o Estado do Paraná. De acordo com Nimer (1979), o norte apresenta 1 a 2 meses secos no inverno decorrentes do decréscimo das chuvas trazidas pelas correntes perturbadas pela invasão da frente polar. O autor utiliza a denominação de "período seco" de acordo com a definição de Gaussen e Bagnouls.

Nimer (1979) coloca que a existência de um período seco, no inverno, atinge uma pequena área no noroeste paranaense, que se verifica com muita regularidade e que, margeando esta região, há um corredor orientado no sentido NE-SW (do nordeste ao sudoeste do Paraná) que consiste numa zona de transição entre o regime de chuvas de duas estações bem definidas, com o máximo de verão e seca do inverno do Brasil tropical e o regime de chuvas bem distribuídas, que é característico do Brasil de clima temperado.

Assim, a precipitação de inverno é mais expressiva na porção mais meridional, de clima mais temperado, enquanto uma precipitação com estiagens fracas no inverno ocorre em clima mais setentrional, mais ao norte do estado, em clima subtropical.

Entretanto, o norte do Estado, comparado ao sul, não é somente diferenciado pela precipitação entre os meses do ano, mas também pela variabilidade interanual.

Souza (2006) estimou com dados de 43 estações entre 1972 a 2002 que o desvio padrão da precipitação interanual é maior para região sul do estado do que para a região norte, com valores absolutos entre 400 a $540 \mathrm{~mm}$, enquanto na região Norte, estes não ultrapassam $240 \mathrm{~mm}$. Já o coeficiente de variação mostra que a variabilidade não passa dos $27 \%$, da dispersão em relação ao valor médio, no Sul e $18 \%$, ao Norte do Estado.

Aplicando-se a Análise de Componentes Principais às variáveis classificatórias (Total, JJA, DET, DJF), observa-se que duas componentes principais explicam 99,109 $\%$ da variação dos dados. Portanto, é possível substituir a matriz de dados de ordem $469 \times 4$ por outra com as componentes principais de ordem $469 \times 2$. Além da redução dos dados, têm-se duas variáveis independentes. A primeira componente principal é dominada pelas variáveis JJA e Total, enquanto que a segunda componente é dominada pelas outras duas variáveis: DET e DJF. (Tabela 2). Isto demonstra que os descritores empregados discriminam satisfatoriamente as amostras analisadas. 
Tabela 2. Peso das componentes principais

DET

DJF

JJA

Total

\section{Componente 1}

$-0,327861$

0,251073

0,653623

0,634229

\section{Componente 2}

0,66093

0,699991

$-0,153505$

0,222757

Tabela 3. Autovalores e variância explicada

Número da Componente Autovalor

$\begin{array}{ll}1 & 2,22262 \\ 2 & 1,74175 \\ 3 & 0,0356351 \\ 4 & 3,45563 \mathrm{E}-16\end{array}$

Percentual da Variância

55,565

43,544

0,891

0,000
Percentual Acumulado da Variância

55,565

99,109

100,000

100,000

Analisando o gráfico de Componentes Principais (Figura 1), observa-se que:

1. Da tabela 4 tem-se que o total da média da precipitação anual (Total) está correlacionada fortemente com o total da média da precipitação de inverno (JJA), $\hat{\rho}=0,8483$. Ou seja, onde há precipitação mais elevada no inverno é também onde ocorrem as maiores precipitações do estado. E, o gráfico das componentes principais (Figura 1) mostra o agrupamento dessas duas variáveis na primeira componente, tendo em vista os seus altos pesos.

2. Da mesma forma, da tabela 4, nota-se que DET e DJF têm correlação moderada, mas significativa, $\hat{\rho}=0,6216$. E, quanto maior a diferença entre os trimestres de verão e inverno (DET), maior a precipitação de verão (DJF). Ou seja, nas regiões de menor pluviometria, há maior diferença entre trimestres e as chuvas se concentram mais no verão. Estas regiões são do norte do estado, onde o clima é mais seco e há períodos secos no inverno. O agrupamento dessas variáveis pode ser visto no gráfico (Figura 1).

Tabela 4. Correlação de Pearson entre as variáveis (DET, JJA, DJF, e Total) e valor $P$.

$\begin{array}{lllll} & \text { DET } & \text { DJF } & \text { JJA } & \text { Total } \\ \text { DET } & & \mathbf{0 , 6 2 1 6} & \mathbf{- 0 , 6 5 4 5} & -0,2036 \\ \text { Valor P } & & 0,0000 & 0,0000 & 0,0000 \\ \text { DJF } & \mathbf{0 , 6 2 1 6} & & 0,1854 & \mathbf{0 , 6 1 4 3} \\ \text { Valor P } & 0,0000 & & 0,0001 & 0,0000 \\ \text { JJA } & \mathbf{0 , 6 5 4 5} & 0,1854 & & \mathbf{0 , 8 4 8 3} \\ \text { Valor P } & 0,0000 & 0,0001 & & 0,0000 \\ \text { Total } & -0,2036 & \mathbf{0 , 6 1 4 3} & \mathbf{0 , 8 4 8 3} & \\ & 0,0000 & 0,0000 & 0,0000 & \end{array}$

Nota: Valores-p abaixo de 0,05 indicam correlações (não nulas) estatisticamente significativas ao nível de $95,0 \%$ de confiança 


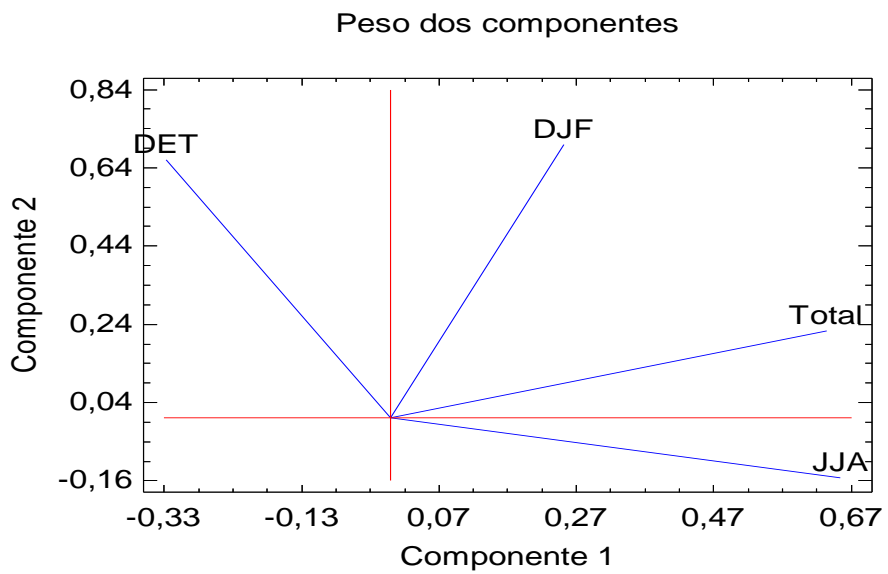

Figura 1. Relação entre as componentes principais

Nota: DET- Diferença ente trimestres; DJF - total da precipitação de dezembro, janeiro e fevereiro; Totaltotal da precipitação anual; JJA - total da precipitação de junho, julho e agosto

De acordo com MUÑOZ et al. (1992), em uma figura que represente a ACP (Análise de Componentes Principais), vetores com medidas mais distantes de zero, correspondem a variações com maior influência sobre o valor do Componente Principal, enquanto que, vetores mais próximos de zero, indicam que correspondem a uma variável com pequena influência sobre o Componente Principal. Portanto, é possível verificar que todas as variáveis classificatórias correspondem a variações de forte influência.

Os atributos JJA e Total (positivamente), contribuíram com maior peso sobre a variabilidade associada ao primeiro eixo (Componente Principal 1). Os atributos DJF e DET (positivamente) contribuíram com maior influência sobre o Componente Principal 2.

As amostras ficaram bem distintas umas das outras, marcadas pelas localizações bem definidas de cada uma no gráfico bidimensional.

As correlações entre as variáveis classificatórias podem ser vistas na tabela 4 , sendo que as correlações fortes estão grifadas em negrito.

Com base na aplicação da análise de agrupamentos, feita pelo método hierárquico da variância mínima (Ward, 1963), foram definidos 14 grandes grupos de observações pluviais no Estado do Paraná (Figura 2). 


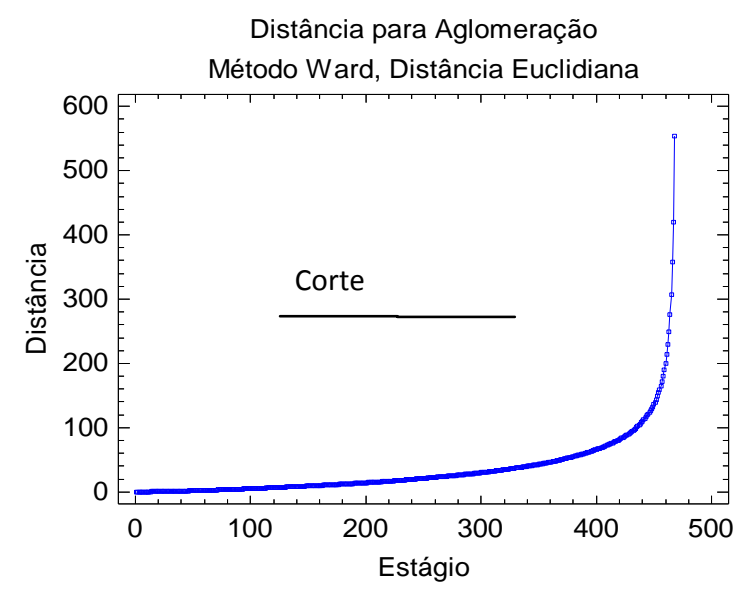

Figura 2. Gráfico da distância para aglomeração

Nota: Corte no número 14

Após definido 14 como sendo o número de grupos formados, aplicou-se o método das K- médias, sendo que o resultado gráfico pode ser visualizado nas Figuras 3 e 4. Essas figuras apresentam a relação entre o DET e DJF (Figura 3) e o JJA e Total (Figura 4).

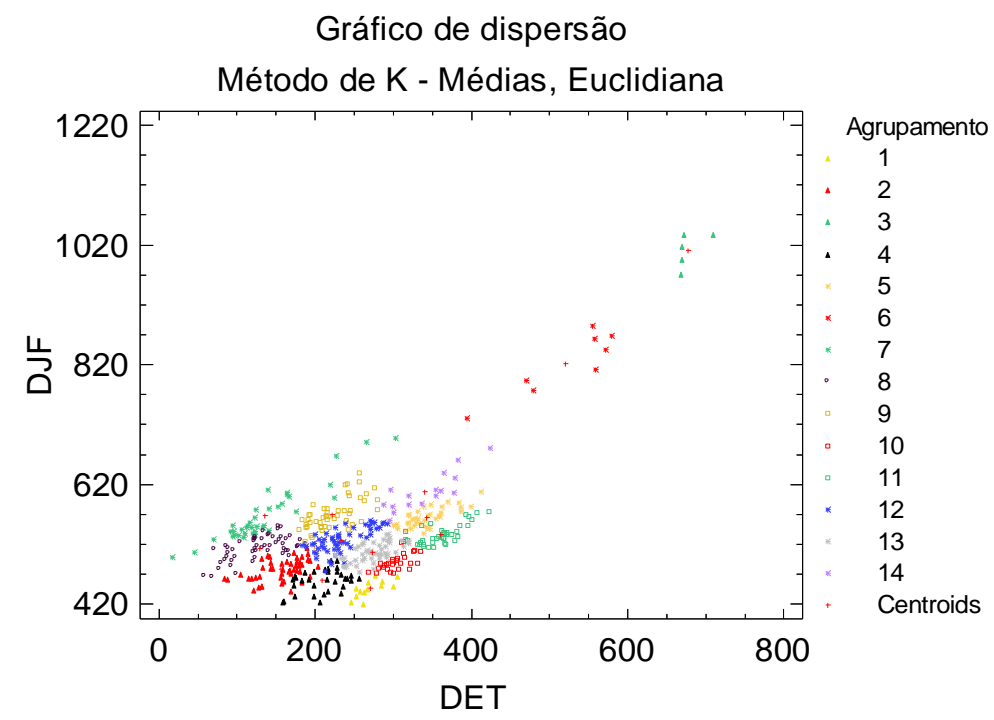

Nota: DJF - meses de dezembro, janeiro e fevereiro; DET - diferença entre trimestres

Figura 3. Grupos formados (Método K - Médias, distância Euclidiana) com os componentes DJF (precipitação de dezembro, janeiro e fevereiro) e DET (diferença entre precipitação de verão e de inverno). 
Gráfico de dispersão

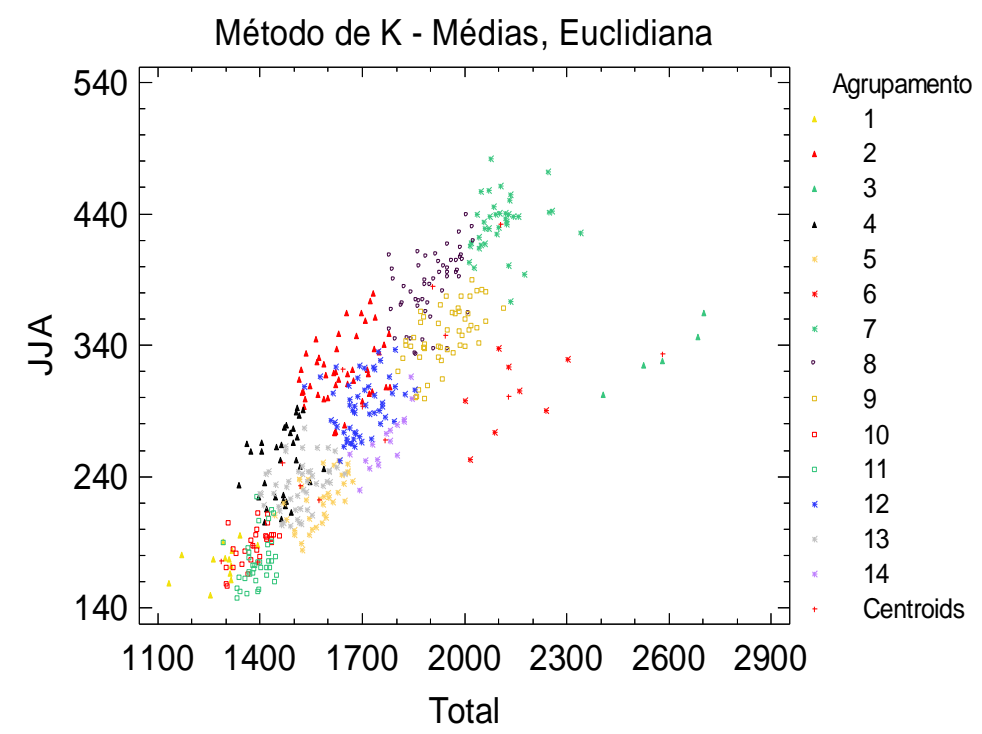

Nota: JJA - meses de junho, julho e agosto; Total - total médio anual de precipitação

Figura 4. Grupos formados (Método K - Médias, distância Euclidiana) com os componentes JJA (precipitação de junho, julho e agosto) e Total (precipitação total anual)

Estes grupos foram plotados na carta hipsométrica (Figura 5), onde foi verificada a consistência ambiental dos agrupamentos. Eles foram denominados da seguinte forma: 1. Noroeste (Divisa bacias do Paraná e Paranapanema); 2. Segundo Planalto (Bacia do Alto Iguaçu); 3. Litoral (Bacia Litorânea); 4. Campos Gerais (Bacia do Piquiri e Ivaí); 5. Região de Londrina e Maringá (Região de Londrina e Maringá); 6. Serra do Mar (Bacia do Alto Paranapanema), 7. Sudoeste A; 8. Sudoeste B; 9. Bacia do Ivaí e Piquiri; 10. Primeiro Planalto (Ribeira, Tibagi e Iguaçu); 11. Norte do Estado, Divisa com São Paulo; 12. Próximo ao Paralelo 24ㅇ; 13. Nordeste / Noroeste; 14. Baixo Ivaí.

A discussão dos grupos será feita de acordo com a interpretação destas figuras, associadas à carta hipsométrica (Figura 5) onde as estações estão localizadas. Analisando as figuras 3 e 4 observa-se, no geral, um nítido gradiente de precipitação, bastante evidente na precipitação total (Total) e na de inverno (J,J,A). Assim, podemos considerar três grandes grupos no estado: um com estiagem de grau variável no inverno, outro com a precipitação mais uniforme durante o ano e um terceiro grupo intermediário entre os dois. 


\section{A - Grande grupo com "estiagem" no inverno}

Todo este grupo situa-se desde o limite norte do Estado até o paralelo $24^{\circ} 00^{\prime} \mathrm{S}$. O grupo tem em comum o fato de estarem situados em latitudes próximas e em relevos semelhantes e, em geral, de baixa altitude (abaixo de $400 \mathrm{~m}$ ). Isto também foi evidenciado por Souza (2006), que fez uma análise de um transecto traçado no paralelo $23^{\circ}$ e observou a homogeneidade de relevo das estações da porção norte do Estado.

O grupo 1 é exclusivo do extremo noroeste, próximo à junção dos paralelos 2300' S e 5300' W, onde há áreas de menor precipitação do Estado e também onde há estiagem no inverno. Hidrograficamente corresponde à bacia do Paraná 2. Também com o mesmo montante médio de precipitação de inverno está o grupo 11 (calha do Médio Paranapanema 1, 2 e 3) que apresenta uma dispersão espacial maior no norte e nordeste do estado e também do grupo 6 (Alto Paranapanema) que apresenta uma forte concentração das estações (Figura 4). Com uma precipitação relativamente mais elevada de inverno e uma distribuição espacial mais dispersa, temos o grupos 13 (nordeste /noroeste), 14 (Foz do Ivaí) e 5 (Região de Londrina e Maringá).

\section{B- Grande grupo com precipitação mais uniforme durante o ano}

Neste grande grupo, encontramos três grupos: um no leste do Estado e dois na porção sudoeste do Estado.

O grupo 3 (Litoral) se destaca nitidamente dos demais pela elevada precipitação total anual e também elevada precipitação nos meses de verão (DJF). Entretanto, neste grupo, a precipitação de inverno não é mais alta, em média, do que para o grupo 7 e também para o grupo 8. Este grupo de estações do litoral apresenta um comportamento bastante diferenciado, como se pode notar nos gráficos da figuras $3 \mathrm{e}$ 4. Fritzsons et. al, 2008, também observaram a distinção deste grupo também em relação a temperatura média do estado.

O grupo 8 se confunde com 0 grupo 7 , estando ambos concentrados no baixo Iguaçu e baixo Chopin, em altitudes menores (600 a $700 \mathrm{~m}$ ), comparado a altitude média da região sul, e apresentam grande homogeneidade em termos do total de precipitação anual, mas também grande variação em termos de precipitação de inverno. 


\section{$\underline{\text { C- Grupo intermediário }}$}

Neste grande grupo encontram-se os grupos 2, 4, 9, 10 e 12, localizados na parte central do gráfico e porção central e sul-sudeste do estado.

Os grupos 10 (Primeiro Planalto e Segundo Planalto) e 12 (Centro Norte) se assemelham em termos de quantidade de precipitação de inverno. Destes, o grupo 12 apresenta uma precipitação mais elevada no verão (D, J, F) e total, e o grupo 10 apresenta menor precipitação total e menor precipitação no verão. Deve se observar que o grupo 12, embora apresente uma distribuição geral na porção norte do estado, os postos pluviométricos estão predominantemente localizados nos locais de maiores altitudes.

O grupo 9 (central), localizado na porção central do Paraná, ocupa uma posição intermediária no gráfico ( Fig. 3 e 4) e apresenta a mesma precipitação de inverno do grupo 2, que se localiza no Alto da Bacia do Iguaçu e Tibagi. Quanto ao grupo 4, apresenta-se disperso nos vales dos rios Ivaí e Piquiri e também na porção leste da bacia do Tibagi, próximo ao município de Castro.

Assim, verifica-se que a relativa homogeneidade presente no norte do Estado não se verifica no sul. Para Souza (2006) isto é devido ao fato de que a continentalidade é uma característica influente na precipitação. A autora ressalta que na região cortada pelo Trópico de Capricórnio, em determinados períodos, principalmente no verão, a região Noroeste sofre a influência da massa tropical continental associada à baixa pressão do Chaco (massa tropical seca), que inibe a atuação das frentes frias.

$\mathrm{Na}$ porção sul do estado, há uma maior heterogeneidade que, de acordo com Souza (2006), pode ser atribuída à interação entre as características do relevo, as constantes entradas de sistemas frontais associados ao jato subtropical, da Alta da Bolívia - faixa de circulação anticiclônica na alta troposfera, da atuação de massas de ar quentes e úmidas como, por exemplo, em baixos níveis, a Zona de Convergência do Atlântico Sul nos períodos de primavera e verão.

Deve se observar também que o médio Vale do Ribeira, no leste do Estado, sendo circundado por serras e planaltos elevados a mais de $1000 \mathrm{~m}$, assume um comportamento pluviométrico bastante aproximado ao do norte paranaense na calha do rio Paranapanema.

Outro fator a ser analisado é que há estações que foram agrupadas pelo teste estatístico e não estão agrupadas espacialmente. Isto pode ser decorrente da 
localização específica da estação meteorológica (situação de barlavento, sotavento, altitude, etc.).

$\mathrm{Na}$ porção leste do Estado a maritimidade, associada às escarpas elevadas da Serra do Mar, é responsável pelos maiores índices pluviométricos do Estado. As chuvas orográficas ocorrem aí tanto por incidência de correntes, de direção aproximadamente perpendicular ao relevo, em escala sinótica de leste e sudeste, quanto pela brisa marítima da tarde e início da noite, ambas de direção aproximadamente perpendicular ao relevo. A precipitação é significativamente maior quando comparada ao interior do estado, mostrando que o fenômeno de precipitação pluvial é produzido sob diversas condições meteorológicas.

\section{CONCLUSÕES}

As análises estatísticas utilizadas neste trabalho foram úteis para compreensão da dinâmica da precipitação no Estado do Paraná. A interpretação das análises evidenciou a diversidade climática que ocorre no estado, que se situa numa área de transição entre o tropical (sudeste) e temperado quente (sul) do País e apresenta um relevo também diferenciado. Apesar desta diversidade, utilizando-se apenas os dados de pluviometria, foi possível agrupar estações semelhantes. Além desta, outras conclusões foram obtidas:

1. As médias dos totais de precipitações de inverno e verão em conjunto com a precipitação total anual emergem como duas variáveis importantes para a definição das regiões pluviométricas, mesmo considerando um período fixo para o verão (dezembro, janeiro e fevereiro) e para o inverno (junho, julho e agosto).

2. Nas regiões de menor pluviometria, há maior diferença entre trimestres e as chuvas se concentram mais no verão. Estas regiões são as do norte do estado, onde o clima é mais seco e há estiagens de inverno em pelo menos um mês.

3. As regiões de maior pluviometria são as do sudoeste do estado e do litoral. No sudoeste ocorrem as maiores alturas de precipitações de inverno do Estado. No litoral, as chuvas de verão conferem um maior peso na precipitação total.

4. O grupo de estações do litoral separou-se de uma forma muito nítida dos demais grupos nas análises efetuadas. Isto decorre da multiplicidade de fatores condicionadores de chuva ao longo da costa e da Serra do Mar, tanto de 
mesoescala como de microescala, que se agregam aos fatores sinóticos: orografia, terral, brisa marítima, contrastes térmico entre terra e oceano e águas interiores.

5. Há uma zona intermediária, situada na região central do estado, mas com entradas na região do planalto sudeste, em que os grupos foram muito dispersos, o que impossibilitou o agrupamento espacial utilizando as variáveis do trabalho. Nesta região, na tentativa de realizar o agrupamento espacial, deverão ser utilizadas outras variáveis climáticas para a discriminação de grupos como, por exemplo, a temperatura do ar, umidade relativa, etc.

6. As condições pluviométricas no Paraná asseguram, de forma geral, uma boa recarga dos sistemas aquíferos o que é evidenciado pela ausência de déficits hídricos em média. Isto assegura também a consequente manutenção da vazão dos rios face aos episódios de estiagem ao longo do ano. Nos setores onde o solo e o subsolo oferecem boas condições de infiltração de água, a recarga é assegurada, caso do Terceiro Planalto, tanto em sobre os basaltos quanto sobre os arenitos. Nos basaltos o processo é otimizado pois são recobertos por solos e regolito com boas características físicas para a permeabilidade e suas camadas apresentam elevado índice de fraturamento.

7. A distribuição mais uniforme das chuvas ao longo do ano, particularmente ao sul do Trópico de Capricórnio, é particularmente favorável às atividades florestais e à exploração do potencial hidroelétrico dos rios. Graças à recarga dos aqüíferos estes conseguem manter vazões mínimas fluviais relativamente elevadas o que viabiliza muitos projetos de pequenas usinas hidroelétricas.

8. Entretanto, deve-se lembrar que há situações diferenciadas, não apenas decorrente de latitude e longitude, mas também de altitude e situação geográfica, como a do Vale do Ribeira, distinto de outras regiões do Paraná e assim como das áreas circunvizinhas.

\section{REFERÊNCIAS}

ANDRADE, L.A. de; REIS, M. das G.F.; REIS, G.G. dos; COSTA, L.M. da. Classificação ecológica do estado da Paraíba. Delimitação e caracterização de subregiões ecológicas a partir de variáveis biopedológicas. Revista Árvore, Viçosa, v.24, n.2, p.207-214, 2000. 
BERNARDES, L. R. M. Determinação de regiões pluviometricamente homogêneas no estado do Paraná, através de técnicas de análise multivariada. 1998. Tese (Doutorado em Engenharia de Transportes) - Universidade de São Paulo. São Paulo, 1998.

DINIZ, G.B. BERLATO, M.A., CLARKE, R. T., FONTANNA, D. C. Identificação de regiões homogêneas de temperaturas máximas e mínimas no Rio Grande do Sul. Revista Brasileira de Agrometeorologia, Santa Maria. V.11, n.2, p. 303-312. 2003.

FALVO, G.; RIZZI, N. E.; CHAVES NETO, A. Zoneamento da bacia hidrográfica do Rio Miringuava utilizando-se de técnicas de análise multivariada. Revista do Setor de Ciências Agrárias </b>, Curitiba, v. 15, n. 2, p 15-32, 1996.

IBGE Instituto Brasileiro de Geografia e Estatística. Disponível em http://www.ibge.gov.br/estadosat/perfil.php?sigla=pr. Acesso em 22 de fevereiro de 2010.

IAPAR. Instituto Agronômico do Paraná. Cartas climáticas do Paraná. Disponível em http://www.iapar.br/modules/conteudo/conteudo.php?conteudo=863. Acesso em 17 de fevereiro de 2010.

FRITZSONS, E. MANTOVANI, L. E., VIRGINIA DE AGUIAR, A. Relação entre altitude e temperatura: uma contribuição ao zoneamento climático no Estado do Paraná. Revista de Estudos Ambientais, v.10, p.40-48, 2008.

FRITZSONS, ELENICE; MANTOVANI, L. E.; CARPANEZZI, A. A. ; WREGE, M.; GARRASTAZU, M. C.; CHAVES NETO, A. . Ecological Regions Map for Forest plantation at Paraná State, Brazil. In: XIII Congresso Forestal Mundial, 2009, Buenos Aires.

FRITZSONS, E., MANTOVANI, L., WREGE, M.. Carta de unidades geoclimáticas para o Estado do Paraná para uso florestal. Pesquisa Florestal Brasileira, América do Norte, 30, out. 2010. Disponível em: http://www.cnpf.embrapa.br/pfb/index.php/pfb/article/view/162. Acesso em: 14 Jan. 2011.

HAIR Jr., J.F.; ANDERSON, R.E.; TATHAM, R.L.; BLACK, W.C. Análise Multivariada de Dados 5a. Ed. (trad.). Porto Alegre: Bookman, 2005. 593p.

IAPAR. Instituto Agronômico do Paraná. Cartas climáticas do Paraná. Disponível em http://www.iapar.br/modules/conteudo/conteudo.php?conteudo=863. Acesso em 17 de fevereiro de 2010.

ITCG (Instituto de Terras, Geografia e Geociências) Clima - Estado do Paraná. Disponível

em http://www.itcg.pr.gov.br/modules/conteudo/conteudo.php?conteudo=47. Acesso em 24 de maio de 2011.

KELLER FILHO, ASSAD, E. D., LIMA, P. R. DE R. Regiões pluviometricamente homogêneas no Brasil. Pesquisa Agropecuária Brasileira (PAB). Brasília, v.40, n.4, p.311-322. 2005.

MOITA NETO, José Machado; MOITA, Graziella Ciaramella. Uma introdução à análise exploratória de dados multivariados. Quím. Nova, São Paulo, v. 21, n. 4, July 1998 . Disponível em http://www.scielo.br/scielo.php?script=sci_arttext\&pid=S0100- 
40421998000400016\&Ing=en\&nrm=iso $>$. Acesso em 10 de fevereiro de 2010. doi: 10.1590/S0100-40421998000400016.

MUÑOZ, A.M., CIVILLE,G.V., CARR, B.T. Sensory evaluation in quality control. New York: Van Nostrand Reinhold, 1992. 240 p.

NIMER, E. Climatologia do Brasil. Rio de Janeiro: IBGE, 1979. 422p.

REIS, M. das G.F.; LEONARDO, A. de A.; REIS, G.G. dos.; SOUZA, L. de S. Classificação ecológica do Estado da Paraíba. 2. Delimitação e caracterização de regiões ecológicas a partir de variáveis climáticas. Revista Árvore, Viçosa, v.23, n.2, p.139-149, abr./jun. 1999.

SAMIFS. Sistema de Monitoramento de incêndios e estado da vegetação por satélites. Disponível em http://200.189.113.82/mapserver/samifs/. Data da disponibilidade: 20de fevereiro de 2010.

SEIDEL, E. J. ; MOREIRA JUNIOR, F. J. ; ANSUJ, A. P. ; NOAL, M. R. C. . Comparação entre o método Ward e o método K-médias no agrupamento de produtores de leite. Ciência e Natura, v. 30, p. 07-15, 2008. ; Meio de divulgação: Impresso; Série: 1; ISSN/ISBN: 01008307.

SOUZA, P. Estudo da variabilidade climática do Estado do Paraná associado à anomalia TSM no oceano Pacífico. UEM (Universidade Estadual de Maringá. Mestrado em Geografia. 2006.

TRISTAO, R.A.; REIS, M. das G.F.;COSTA, L.M. da; ASPIAZU, C. Classificação ecológica de uma área do Estado de Minas Gerais: um método biopedológico. Revista Árvore, Viçosa, v.21, n.2, p.201-212, 1997.

UNAL, Y.; KINDAP, T.; KARACA, M. Redefining the climate zones of Turkey using cluster analysis. International Journal of Climatology, Istanbul, 23: 1045-1055. 2003.

VENKATESH, B; JOE, M., K. Identifications of homogeneous rainfall regimes in parts of western Ghats regions of Karnataka. Journal Earth System Science, Índia. n.4. 2007.

WILLIAMS, CAROL L.; HARGROVE, WILLIAM W.; LIEBMAN, MATT; JAMES, DAVID E. Agro-ecoregionalization of lowa using multivariate geographical clustering, Agric. Ecosystems and Environment. (2008). Disponível em: http://www.treesearch.fs.fed.us/pubs/31799. Acesso: outubro de 2010. 


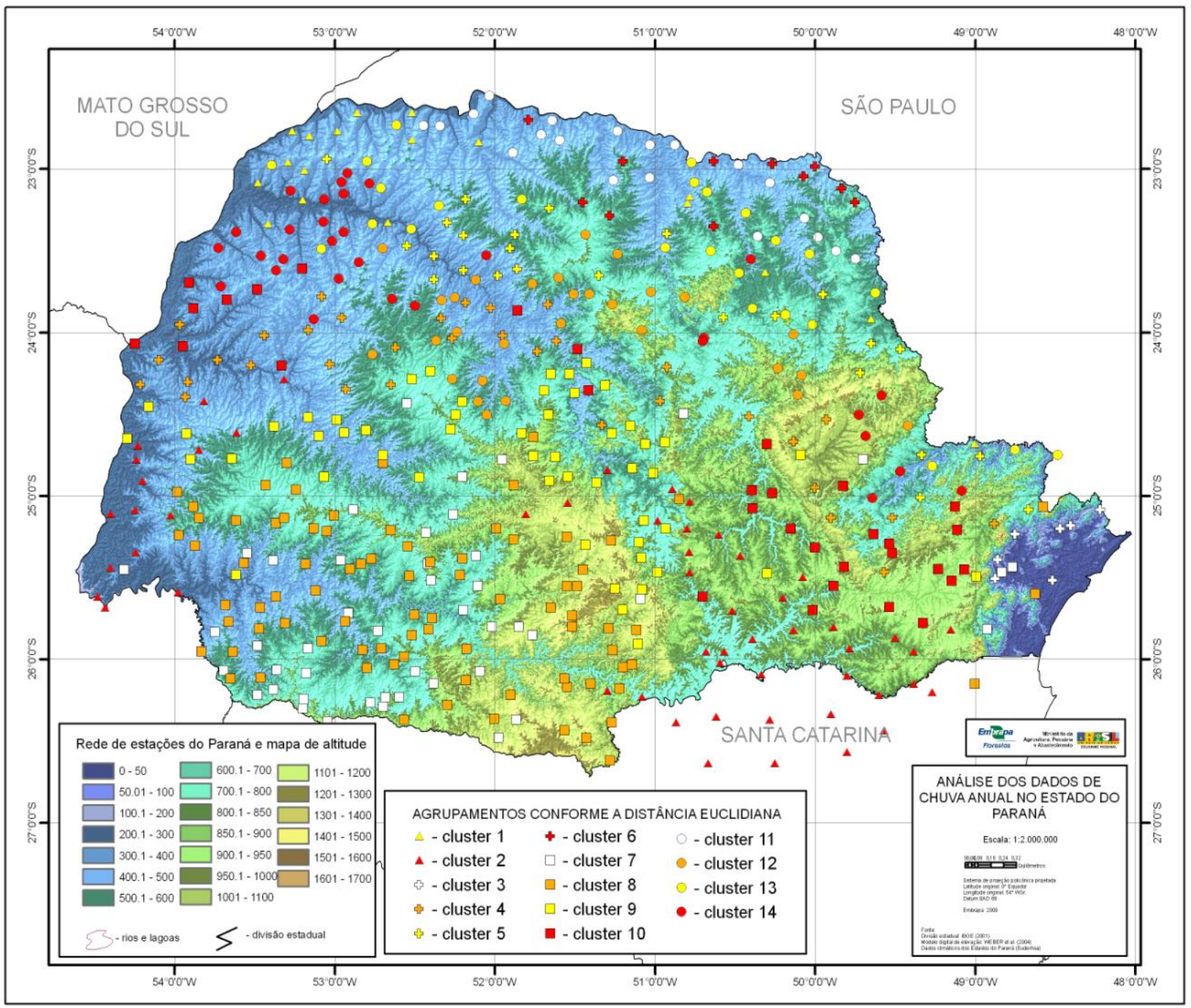

Figura 5. Carta hipsométrica do Estado do Paraná com o agrupamento das estações pela análise de Cluster 